\title{
CONFLITOS SOCIOAMBIENTAIS PELO USO DA ÁGUA EM COMUNIDADES RIBEIRINHAS NO NORDESTE PARAENSE: O CASO DAS BACIAS HIDROGRÁFICAS DOS RIOS MURUCUPI E DENDÊ NO MUNICÍPIO DE BARCARENA-PA
}

\author{
Carlos Bordalo ${ }^{(a)}$, Diego Ferreira ${ }^{(b)}$,Flávia Silva ${ }^{(\mathrm{c})}$ \\ ${ }^{(a)}$ Professor Dr da Faculdade de Geografia e Cartografia, Universidade Federal do Pará, \\ Email:carlosbordalo@oi.com.br \\ (b)Professor Msc do Colégio Militar de Belém, Email: diegocapitao05@yahoo.com.br \\ ${ }^{(c)}$ Professora Msc da Faculdade Integrada Brasil Amazônia, Email e professora da rede pública do estado do Pará: \\ flavia_adriane@yahoo.com.br
}

\section{EIXO: BACIAS HIDROGRÁFICAS E RECURSOS HÍDRICOS: ANÁLISE, PLANEJAMENTO E GESTÃO}

\begin{abstract}
Resumo
Registra-se atualmente um aumento considerável nos conflitos envolvendo o recurso natural água, seja em escala local, regional e até internacional. No entanto, alguns estudos como os de Lanna (1997), Petrella (2002), UNESCO (2003), Vianna (2005) e Torres (2007), que procuraram compreender esses conflitos, não são suficientes para analisar o crescente número de disputas pelo recurso água, ainda mais na Amazônia, que por apresentar considerável riqueza hídrica, vem sendo palco de disputas pelo uso desse recurso tão importante para seus habitantes. Nesse sentido, este artigo objetiva analisar os conflitos envolvendo o uso do recurso hídrico na atividade minero-metalúrgica e as comunidades ribeirinhas no município de Barcarena, no Estado do Pará. O método aplicado foi à análise de hidroterritórios, com base em três variáveis correlacionadas: as categorias Espaço, Tempo e Intenções dos atores. $\mathrm{O}$ resultado deste estudo aponta para a existência de um hidroterritório de luta gerado pela escassez qualitativa de água.
\end{abstract}

Palavras chave: Conflitos, Recurso Hídrico, Hidroterritório, Barcarena, Pará.

\section{Introdução}

O Planeta Terra é formado, em grande parte, por água, sendo que $70 \%$ de sua superfície é coberta por esse líquido essencial à vida, o que a torna um dos recursos mais abundantes do planeta. No entanto, é preciso que se faça uma ressalva: de acordo com UNESCO (2003), de toda água existente apenas 2,5\%, referente a água doce, pode ser facilmente usada para o consumo humano, após adequação de suas características, físicas, químicas e biológicas, tornando-a potável. Assim, embora pareça ilimitada, na verdade essa abundância hídrica representa um obstáculo, pois à medida que há crescimento econômico e populacional, a sociedade de consumo desrespeita o ciclo natural da água e, em consequência, essa vem sendo degradada e se tornando imprópria para consumo em muitas bacias hidrográficas e lacustres. 
Isso mostra que o aumento do consumo, diretamente ligado ao aumento da população, a dinâmica da produção e da distribuição aceleram a degradação ambiental. E esses crescimentos populacionais e do consumo, no caso da água, se traduzem em mau uso (desuso), cujos custos ambientais terminam por serem internalizados pelo recurso hídrico e se refletem na escassez e na poluição, entre outros (CAMARGO, 2003).

Considerando as bacias hidrográficas brasileiras é possível verificar que dentre elas, a bacia Amazônica é a de maior riqueza hídrica. Graças a essa riqueza hídrica, a água na Amazônia é primordial para a sociedade porque, além de sua função fisiológica, ela representa o principal meio de transporte e de obtenção de energia e de produção de alimento. No entanto, algumas formas de uso e exploração da água podem causar diversos impactos sociais e ambientais, comprometendo os demais usos.

No entanto, segundo Vianna (2005), o grande potencial hídrico brasileiro não é suficiente para evitar conflitos por água no território nacional. Conflitos esses gerados não essencialmente pela falta d'água, mas por uma distribuição desigual dos recursos entre classes.

Como é o caso estudado no município de Barcarena - PA, onde a falta de uma gestão local dos recursos hídricos, que deveria ser de responsabilidade do poder público (estadual e municipal), pode agravar a já desigual distribuição social da água, visto que foi identificado um vínculo existente entre os agentes responsáveis pela gestão e grupos privados interessados na sua apropriação como, por exemplo, nas disputas que envolvem o uso da água pela atividade minero-metalúrgica e os ribeirinhos, como no caso nas Bacias Hidrográficas dos Rios Murucupi e Dendê. O município de Barcarena está localizado no estado do Pará, na Mesorregião Metropolitana de Belém, mais precisamente na Microrregião de Belém. A sede do município apresenta as seguintes coordenadas geográficas: $01^{\circ} 30^{\prime} 24^{\prime}$ ' de latitude Sul e 48³7’12' de longitude a Oeste de Greenwich. (Ver figura 01).

Os projetos minerários são muito importantes dentro do contexto socioeconômico do Estado do Pará, devido ao potencial dessa riqueza natural em solo paraense. Dentre os cinco maiores municípios em termos de renda per capita, quatro possuem importantes indústrias minerais na extração de cobre, ferro e bauxita e na transformação de alumina e alumínio, como é o caso do município de Barcarena.

Barcarena foi inserida no ciclo da mineração a partir do beneficiamento primário de minérios como a bauxita e o caulim. O município concentra um importante Polo Industrial de mineração, onde está instalado um complexo minero-metalúrgico, com indústrias metal-mecânicas, dentre as quais se destacam a Alumínio Brasileiro S/A (ALBRAS), que beneficia alumínio primário e a Alumina do Norte do Brasil S/A (ALUNORTE), atualmente a maior usina de beneficiamento de bauxita do mundo, e duas fábricas de beneficiamento de caulim, quais sejam, Pará Pigmentos S/A (PPSA) e Imerys Rio Capim Caulim (IRCC). 


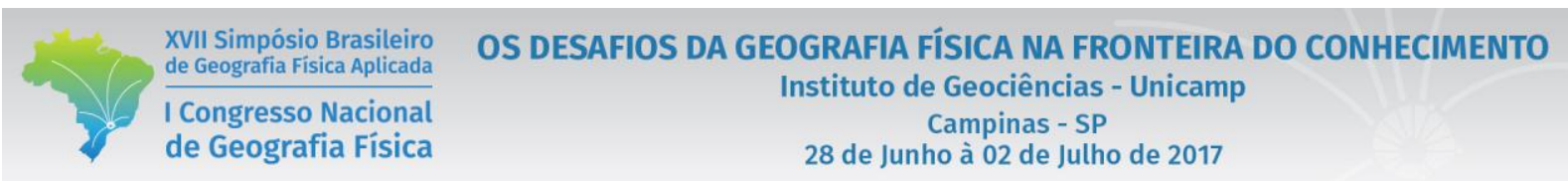

No entanto, o elevado investimento direcionado para atividade minero-metalúrgico vem gerando conflitos envolvendo uso da água entre as indústrias e a população ribeirinha de Barcarena, visto que a atividade mineradora utiliza grande quantidade de água e vem contribuindo para o aumento do risco socioambiental e de conflitos que envolvem os seus recursos hídricos.

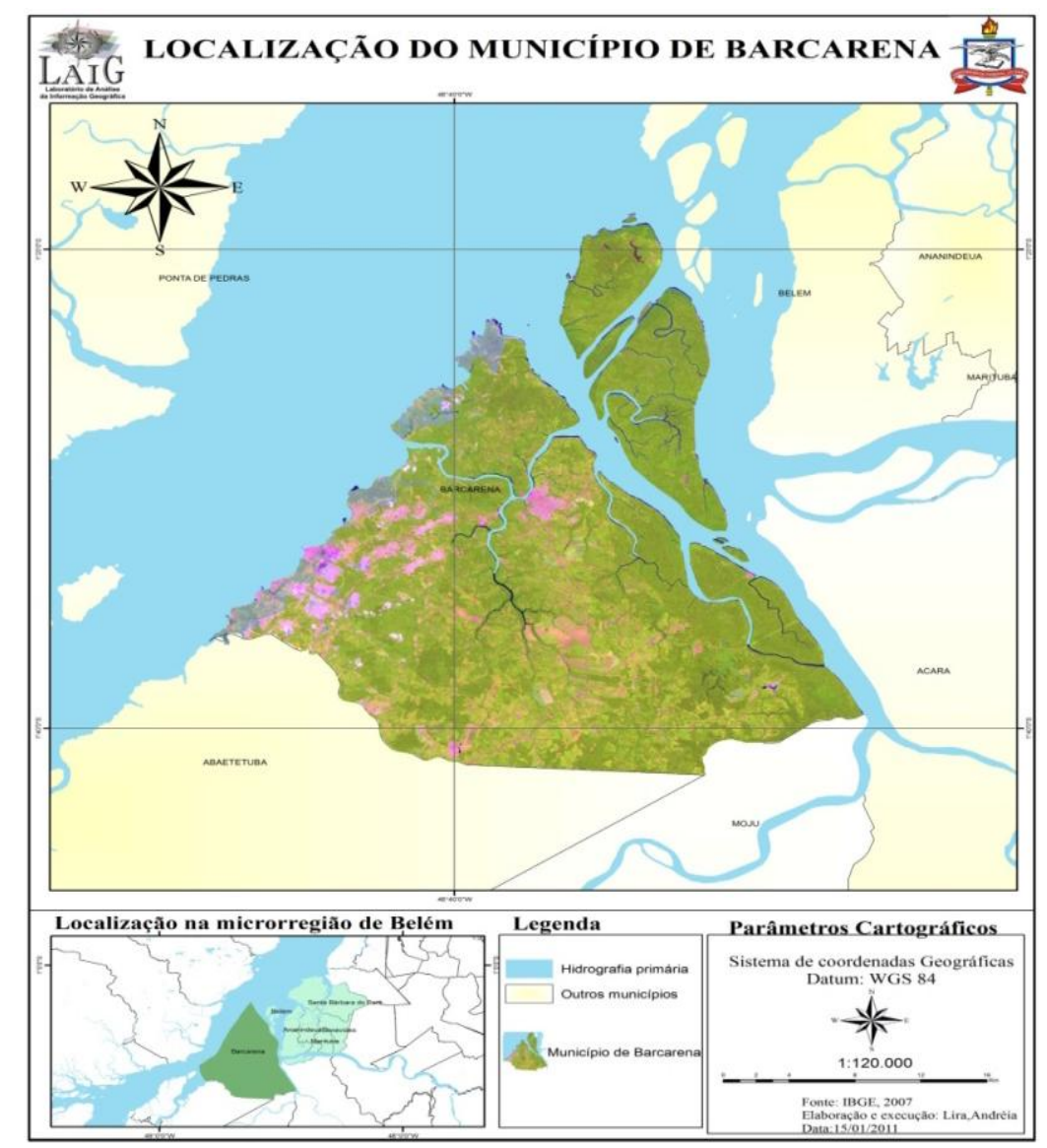

Figura 1 - Mapa de Localização do Município de Barcarena - PA Fonte: FERREIRA, SILVA e LOPES 2011.

\section{Material e Método}

Os procedimentos metodológicos desse artigo estão estruturados em duas partes: pesquisa bibliográfica e documental, e a pesquisa de campo aos corpos hídricos (igarapés), as comunidades ribeirinhas e as empresas envolvidas com a atividade minero-metalúrgica do município de Barcarena. 
Esta pesquisa fez uso das ideias propostas por Thual (1996), que sofreram adaptações em Vianna (2002) para análise de conflitos hídricos e que vêm sendo desenvolvidas para análise de conflitos em torno da gestão dos recursos hídricos e na aplicação da ideia de hidroterritório no semiárido brasileiro, apresentados em diversos trabalhos e estudos realizados no Grupo de Estudos e Pesquisas da Água e Território - GEPAT/ UFPB com, por exemplo, Torres (2007) Vianna (2006) e Lima (2006). Trata-se de uma abordagem nova dentro da geografia brasileira e ainda carece de mais esforços para sistematizar bases teórico-metodológicas melhor alicerçadas.

Dentro da perspectiva do que vem sendo refletido acerca dos hidroterritórios ecom base na obra de Thual (1996), Torres entende que:

(...) para avaliar os territórios demarcados por questões hídricas é necessário observar todos os atores envolvidos nos conflitos para que se possa compreender e avaliar a essência dos fenômenos que alavancam o processo de formação dos hidroterritórios (TORRES, 2007, p.21).

A metodologia avalia principalmente três variáveis correlacionadas, com o objetivo de realizar uma análise do espaço concreto percebido porThualcom a observação dos três vértices do triângulo em pares dialéticos, conforme representada na figura seguinte, a metodologia aponta os eixos considerados fundamentais à análise dos conflitos hídricos:

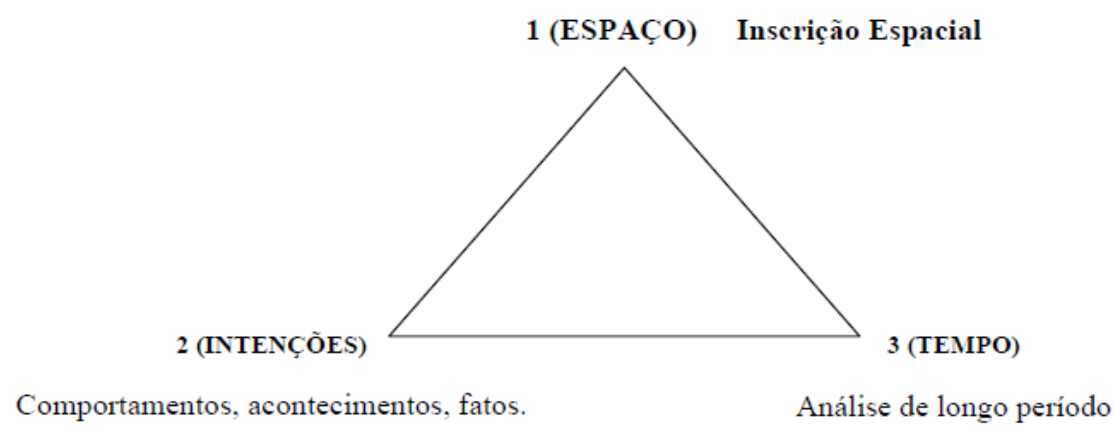

Figura 2.Esquema de análise de conflitos que envolvem a gestão das águas.(TORRES, 2007).

1. Espaço:A inscrição espacial é o espaço de articulação e organização da ação dos atores. Aponta o nível de atuação de cada ator envolvido no conflito.

2. Intenções:A intencionalidade dos atores envolvidos materializa-se no espaço por meio de comportamento e estratégias com a finalidade de conquistar seus anseios. Além disso, revela as contradições das ações sociais destes. É preciso levar em consideração as referências culturais inerentes ao 
espaço de ocorrência do fenômeno. É preciso um olhar apurado das intenções, visto que estas são difíceis de serem discernidas.

3. Tempo: Permite observar as estratégias que os atores utilizam para alcançar seus objetivos no longo prazo, enquanto que as táticas são concretizadas em ações de tempo mais curto. O poder que domina um território por vezes se concretiza ao longo do tempo, num processo histórico que revela, inclusive, a tendência dos agentes do lugar em acatar ou não mudanças.

$\mathrm{Na}$ análise dos hidroterritórios, as categorias Espaço, Tempo e Intenções dos atores (digam-se interesses) devem ser relacionadas. A Intenção pode modificar oterritório através de imposições que tentam alterar o hábito local de gerir a água aolongo do tempo, transformando-o por vezes num hidroterritório, com a interação dealguns atores e resistência de outros, dividindo-os em "classes", os que aceitam(beneficiados), os que acatam e os que se rebelam (prejudicados) contra a nova gestãoda água.

\section{Hidroterritórios e Conflitos Hídricos}

Para Ferreira (2015) ohidroterritório é um conceito ramificado a partir da ideia de território para auxiliar na análise de conflitos que giram em torno da gestão das águas. Com o auxílio de ciências como a Sociologia e Economia e a partir da contribuição de geógrafos como Vianna (2005) e Torres (2007), começam as discussões sobre a categoria hidroterritório dando a Geografia o status de ciência a que cabe seu conceito central. O termo, para os autores citados, significa um fenômeno social onde existe o controle do território, trazendo à tona conflitos e movimentos espaciais e temporais. "Estes movimentos se percebem tanto em temas relacionados com os aspectos humanos como os físicos da Geografia" (TORRES, 2007, p.2).

Esse conceito surge pela necessidade de se pensar a ocupação geopolítica do território a partir das relações de poder exercidas pelos diferentes atores socais utilizando a água como trunfo. A construção desse conceito está relacionada com a existência de múltiplos territórios e das diversas dimensões e escalas em que baliza o conceito de território. Além disso, o hidroterritório está estreitamente associado às dimensões mais "clássicas" do conceito de território; como a política, a econômica e a sociocultural, além da sua dimensão ambiental, permitindo análises que vão do uso e gestão até as relações ambientais que se estabelecem no tempo e no espaço.

Segundo Torres, (2007), entendem-se os hidroterritórios como:

aqueles territórios demarcados por questões de poder político e/ou cultural oriundas da gestão da água, assumindo assim, o papel determinante em sua ocupação. A princípio este território é demarcado pela disputa dos estoques de água, não se restringindo limites aos aquíferos onde estão localizados, podendo inclusive gerar conflito pela posse e 
controle da água, por exemplo, pela implantação de um canal, barragem ou açude entre outras obras hídricas. No aspecto de formação territorial, o hidroterritóriopode assumir dimensões e delimitações múltiplas, a origem e trajetória da água é que vai demarcar seu tamanho e forma (TORRES, 2007, p. 14-15).

As diversas territorialidades muitas vezes geram conflitos, demonstrando o confronto de poder. À medida que uma se sobrepõem a outra acontece à imposição desse poder sobre uma população, se estabelece novas ou mantém antigas práticas no território. A luta como movimento, se expressa como uma inacabável territorialização, até que um dos lados aceite as intervenções do outro. A dinâmica imposta é bastante similar a do mercado, de acordo com o ritmo e a necessidade do Capital. Vianna (2005) sugere, com base nessas ideias, a classificação dos hidroterritórios:

a) Hidroterritórios Privados, totalmente mercantilizados, que expressam um valor econômico por quantidades de água, distinto do pagamento de serviçode tratamento e distribuição;

b) Hidroterritórios de Luta, resistentes à mercantilização e que não reconhecem a água como mercadoria travando assim uma luta de classe, denotados por questões de exploração econômicas e sociais;

c)Hidroterritórios Livres, situação em que a política aplicada de gestão da água deve ser de total socialização, tornando-a inalienável e disponível para as gerações futuras. Esses últimos apresentam raízes profundas da cultura, das crenças e costumes, dos que habitam esse território. Ao negar a prática da água mercantilizada, os aparelhos ideológicos culturais demonstram a autonomia de identidade (VIANNA, 2005, p. 220).

Portanto, o conceito de hidroterritório surge como possibilidade de problematizar os conflitos inerentes às águas. Estes conflitos se caracterizam pela não maximização do uso da águasendo definidos como "os problemas que determinada atividade pode ocasionar a outros usos, chegando, algumas vezes, a torná-los impossíveis" (Mota, 1995), não só pela escassez quantitativa, mas também pela escassez qualitativa de água. Ou seja, um tipo de uso pode impossibilitar outro na medida em que, consome de forma não otimizada a água fazendo com que não haja disponibilidade suficiente para todas as atividades. Da mesma forma, quando uma atividade polui de tal forma o curso d'água que o torna inútil para outras atividades que exigem como requisito básico uma qualidade de água adequada.

Lanna (1997) traz outra categorização de conflitos de uso dos recursos hídricos, e são eles:

* Conflito de destinação de uso: utilização da água para finalidades diferentes daquelas estabelecidas pelo órgão gestor;

* Conflito de disponibilidade qualitativa: utilização de água proveniente de corpos hídricos poluídos para o fim a que se destinam; 
* Conflito de disponibilidade quantitativa: esgotamento da disponibilidade quantitativa devido ao uso intensivo da água.

Sobre as questões referentes aos conflitos hídricos, diversos autores têm se manifestado, entre eles Vianna (2005). Para ele, entre os conflitos pelo uso da água, aquele que opõe o abastecimento público a outros, quaisquer que sejam, é o caso mais comum. Porém, todos os outros usos como energia, navegação, lazer, indústria, agricultura e serviços, apresentam diversas situações de conflitos entre eles, sendo raros os projetos que preveem a utilização múltipla dos recursos hídricos.

Sendo assim o presente artigo discute sobre conflitos hídricos tendo como área de estudo as bacias hidrográficas do rio Murucupi e Dendê, situadas no município de Barcarena. As áreas que foram pesquisadas apresentam uma complexidade no que se refere as formas de uso e ocupação do solo e da água, ao envolverem uma diversidade de atores sociais e atividades urbanas, industriais e rurais.

\section{As bacias hidrográficas dos riosMurucupi e Dendê no Contexto do Pará}

Estado do Pará apresenta uma expressiva rede hidrográfica caracterizada pela existência de 20bacias. O órgão responsável pela efetivação da Lei Estadual n $n^{\circ}$ 6.381/2001 subdividiu o estado em sete regiões hidrográficas, com o objetivo de proporcionar um gerenciamento mais congruente e efetivo dosrecursos hídricos (SILVA, 2012). Sendo assim, temos as seguintes regiões hidrográficas: Região Calha Norte, Região Tapajós, Região Baixo Amazonas, Região Xingu, Região Tocantins-Araguaia, Região PortelMarajó eRegião Costa Atlântica-Norte (LIMA et al, 2005).

As bacias hidrográficas do rio Murucupi e do igarapé Dendê estão inseridas na sub-região Guamá-Mojú, a qual integraa região hidrográfica denominada Região Costa Atlântica-Norte. Segundo Lima e Lima (2005), estaapresenta potencialidades econômicas (indústrias de diferentes setores, mineração de pequeno egrande porte, turismo, navegação, agricultura, pecuária e madeireira) e hídricas (transporte, águasubterrânea, água mineral e recreação). Diante dessa diversidade econômica e hídrica tambémapresenta uma série de problemas ambientais caracterizados pela ocupação irregular do solo, obstrução de cursos d'água, crescimento populacional dos centros urbanos, dentre outros.

A Bacia Hidrográfica do rio Murucupi está situada no Município de Barcarena, o qual faz parte da região nordeste do Estado do Pará. O rio Murucupi, principal curso d'água dessa bacia hidrográfica, apresenta sua nascente localizada conforme as coordenadas obtidas em trabalho de campo01 $1^{\circ} 33^{\prime} 0,00^{\prime \prime}$ de latitude sul e $48^{\circ} 43^{\prime} 0,00^{\prime \prime}$ de longitude oeste e sua foz nas coordenadas de $01^{\circ} 29^{\prime} 31^{\prime \prime}$ de latitude sul e $48^{\circ}$ 40’00,8”' de longitude oeste. (SILVA, 2012). 
XVII Simpósio Brasileiro de Geografia Fisica Aplicada

I Congresso Nacional de Geografia Física
OS DESAFIOS DA GEOGRAFIA FÍSICA NA FRONTEIRA DO CONHECIMENTO

Instituto de Geociências - Unicamp

Campinas - SP

28 de Junho à 02 de Julho de 2017

A nascente principal do rio Murucupi se encontra na área do complexo industrial da empresa Alunorte, posteriormente segue seu percurso cortando a área de Proteção Ambiental, a Vila dos Cabanos, os bairros:Pioneiro e Laranjal, se estendendo pelas terras de comunidades tradicionais e ribeirinhas até desaguar no o Furo do Arrozal (SILVA, 2012). Percebe-se então, uma complexidade nas formas de uso e ocupação do solo e da água na área correspondente a bacia hidrográfica do rio Murucupi.

Ao observar o mapa 4 e por meio de relatos de moradores e de documentos oficiais constatou-se que no trecho em que o rio Murucupi percorre pelas áreas de ocupação urbana (sejam as planejadas ou não), recebe diretamente efluentes domésticos in natura, na forma líquida e sólida, em seu leito, pois essas áreas não apresentam Estação de Tratamento de Esgoto - ETE; o que compromete a qualidade das águas do referido curso d'água e impossibilita o seu uso pelas famílias das comunidades tradicionais, rurais e ribeirinhas que necessitam desse corpo d'água para desenvolverem suas atividades diárias, de subsistência e lazer (SILVA, 2012).

Esta situação se agravou em 2003 e 2009 com a liberação dos efluentes gerados pela atividade de transformação mineral, que por meio do transbordamento dos Depósitos de Rejeitos Sólidos (DRS) da empresa Alunorte, em períodos de elevados índices pluviométricos, acabaram por comprometer mais ainda a qualidade das águas do Rio Murucupi, segundo informações obtidas nos relatórios do Instituto Evandro Chagas (IEC), nos relatórios e autos de infração da Delegacia de Meio Ambiente e Perícias Criminais do Centro de Perícias Científicas Renato Chaves, como podemos observar no parecer do Centro de Pericias Científicas Renato Chaves

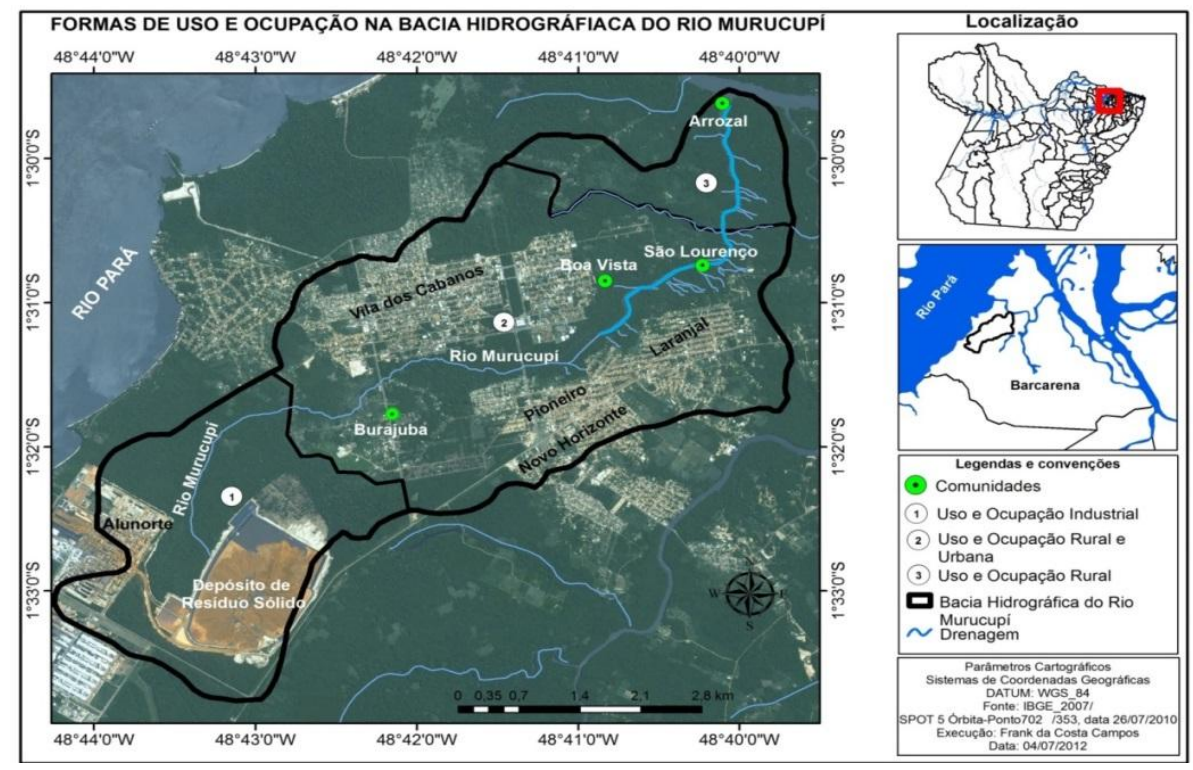

Figura 3. Formas de Uso e Ocupação na Bacia Hidrográfica do Rio Murucupi. (SILVA, 2012) 
Diante do exposto, é imprescindível a gestão das águas na bacia hidrográfica do Murucupi. Tendo em vista seus diferentes usos do solo e formas de ocupação. Esses acontecimentos representam ameaças à sobrevivência dos corpos d'água, a biota e as populações situadas na área da bacia hidrográfica do rio Murucupi e expõem a vulnerabilidade dos recursos naturais e a fragilidade da gestão ambiental e hídrica no município. (BORDALO et al, 2012).

O Rio Dendê nasce nas proximidades da indústria ALBRAS, e suas matas ciliares, em grande parte foram substituídas por outras espécies devido à ação da população que vive ao longo de suas margens

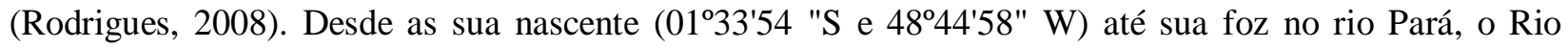
Dendê flui no curso natural, no sentido nordeste/sudoeste, através das comunidades do Bairro Industrial (01³4'09 "S e 4845'25" W), Ilha São João (0134'27 "S e 4845'55 "W) e Praia do Conde (01³4'01" S e $\left.48^{\circ} 46^{\prime} 01^{\prime \prime} \mathrm{W}\right)$.

Já o igarapé Curuperé é um pequeno corpo hídrico que nasce dentro da planta industrial da empresa Imerys RCC, nas proximidades da bacia $\mathrm{n}^{\circ} 05$ de rejeitos de processamento de caulim e desagua no Rio Dendê. Às margens do igarapé Curuperé estão localizadas as comunidades Curuperé $\left(01^{\circ} 34^{\prime} 49\right.$ "S e $48^{\circ} 45^{\prime} 17^{\prime \prime}$ W) e Canaã ( $01^{\circ} 34^{\prime} 45$ W "S e 48 45'52"). Ao longo de quase toda a sua extensão, o rio é coberto por vegetação e suas matas ciliares estão bem conservadas (Lima et. al., 2011). (Ver figura 05).

A área do Complexo Industrial de Barcarena, então, é a inscrição espacial onde as relações do conflito se desenvolvem, pois nela estão inseridos o rio Dendê e igarapé Curuperé, pertencentes a uma APP, as comunidades ribeirinhas Ilha São João e Curuperé e a empresa Imerys RCC. Acrescenta-se, também, o fato do Complexo Industrial de Barcarena ser área de atuação da Companhia de Desenvolvimento Industrial do Pará (CDI) e do Poder Público, seja ele na figura da Prefeitura Municipal de Barcarena, representado por suas secretarias, a Secretaria Estadual de Meio Ambiente e do Ministério Público Federal e Estadual.

A intenção/ação dos atores envolvidos no conflito está ligada com as relações e interesses de cada ator envolvido no conflito com o espaço em questão. Por isso, vale analisar separadamente as motivações de cada um dos atores envolvidos.

As comunidades ribeirinhas Ilha São João e Curuperé vivem às margens dos rios, respectivamente, Dendê e Curuperé, desde antes da construção do Complexo Industrial de Barcarena. Por isso mesmo, as relações existentes entre estas comunidades e seus respectivos corpos hídricos apresentam características de dependência e uso das águas dos rios, além de características culturais e econômicas com essas águas. 
XVII Simpósio Brasileiro de Geografia Fisica Aplicada

I Congresso Nacional de Geografia Física
OS DESAFIOS DA GEOGRAFIA FÍSICA NA FRONTEIRA DO CONHECIMENTO

Instituto de Geociências - Unicamp

Campinas - SP

28 de Junho à 02 de Julho de 2017

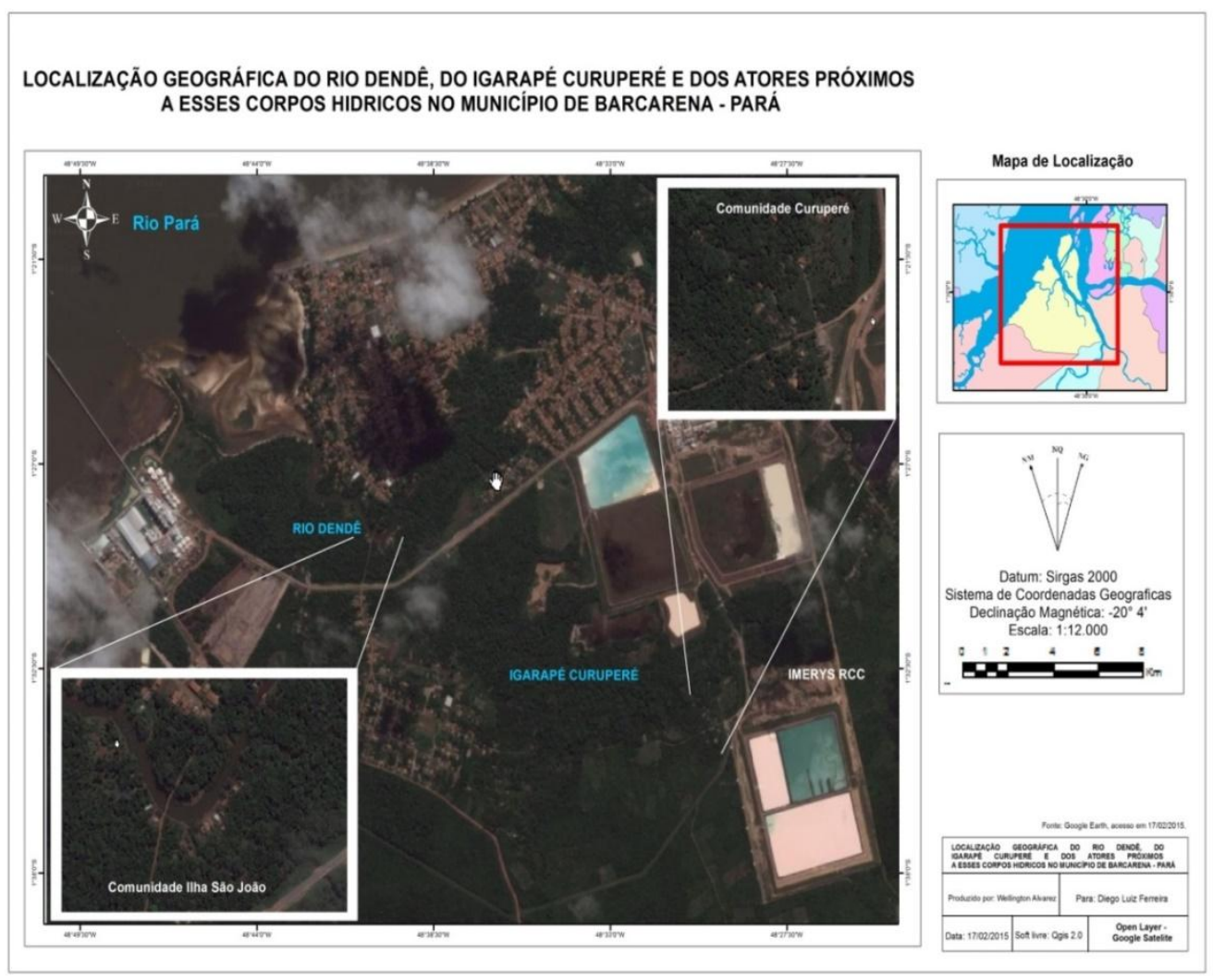

Figura 4. Mapas de Localização da Bacia Hidrográfica do Rio Dendê e Igarapé Curuperé.

(FERREIRA, 2015)

Com a instalação do complexo industrial, ocorreram vários incidentes ambientais que impossibilitaram o uso da água por parte dos moradores destas comunidades ribeirinhas. Essa situação prejudicial fez com que esses moradores se mobilizassem no sentido de defender suas fontes de água. Protestaram, interditando algumas vezes a PA-483, estrada que dá acesso a Vila do Conde ao Porto de Vila do Conde e ao Complexo Industrial de Barcarena. Essa foi a forma que os moradores utilizaram para chamar atenção do poder público, das empresas e da imprensa local sobre a degradação ambiental nos corpos hídricos próximos as empresas, e lutar para ter condições de utilizar a água desses corpos hídricos com condições satisfatórias.

Por fim, o tempo de ocorrência do conflito. Segundo relatos dos moradores das comunidades ribeirinhas envolvidas, no começo da década de 1990, com a instalação de várias fábricas no Complexo Industrial de Barcarena, foi iniciado o conflito, visto que nesse período surgiram as primeiras modificações nos corpos d'água próximos as comunidades. No entanto, com base em pesquisa documental, levaremos em conta os dados referentes à cronologia dos incidentes envolvendo a atividade mineradora e os corpos hídricos no 
município para afirmar que o conflito iniciou juntamente com os primeiros incidentes ambientais registrados no ano de 2003.

Ferreira (2015) comenta que de 2003 a 2014, entre os vários incidentes que ocorreram nos corpos hídricos do município de Barcarena-PA, dois merecem destaque: os vazamentos de caulim da empresa Imerys RCC que atingiram os rios Dendê e Curuperé em junho de 2007 e em maio de 2014. Esses dois incidentes indicam o quanto é grave o conflito, a medida que os mesmo chamaram atenção da imprensa, de políticos, de órgão públicos e do Ministério Público, que, em decorrência desses incidentes firmou, pra cada incidente, um Termo de Ajustamento de Conduta (TAC) com a empresa Imerys. Além disso, esses incidentes expõem que, mesmo com as medidas tomadas pelo poder público, os incidentes continuam, persistindo, também, o conflito.

\section{Considerações}

A legislação sobre recursos hídricos deve ser materializada para que as atividades econômicas e sociais das comunidades situadas na área das bacias hidrográficas dos rios Murucupi e dendê não sejam ainda mais comprometidas e impossibilitando a sobrevivência dessas populações, já que as mesmas estão susceptíveis a sucessivas agressões provocadas pelo lançamento de resíduos industrias e domésticos in natura nas águas dos referidos cursos d'águas.

Portanto, é necessária uma fiscalização rígida e eficiente por parte dos órgãos competentes na fiscalização, bem como um e gerenciamento dos recursos hídricos no município de Barcarena. Cabe ao Estado fomentar a construção conjunta de parcerias com vistas a criação de responsabilidades compartilhadas entre órgãos públicos, instituições privadas e população civil para tentar construir uma participação contínua e ativa em parceria com as comunidades locais na elaboração dos planos de bacia. E ainda deve garantir as seguintes ações: a) materialização dos princípios básicos e os instrumentos da PERH; b) intervenções de atores de intervenções institucionais com articulação entre si, buscando produção de resultados coerentes e justos ao coletivo prevenindo e educando, não somente punindo; c) usar os recursos adquiridos por multas ou parcerias conveniadas de forma transparente e coletiva com o público afetado da bacia hidrográfica; d) canalizarrecursos que viabilize projetos de recuperação, através do planejamento estratégico que vá definir suas problemáticas, discutir prioridades para ir à busca de investimentos junto a seus atores e parceiros, elaborando normas e uma transparência ao usar os investimentos arrecadados.

\section{Bibliografia}


BARROS, M. Mineração, finanças públicas e desenvolvimento local no município de Barcarena-Pará. 2009.

141f. Dissertação (Mestrado em Geografia) - Programa de Pós-Graduação em Geografia, Universidade Federal do Pará, Belém, 2009.

BORDALO, C; SILVA, F; SANTOS, V. Por uma Gestão dos Recursos Hídricos no Estado do Pará: Estudo de caso da Bacia Hidrográfica do Rio Murucupi no Município de Barcarena. REVISTA GEONORTE, Edição Especial, V.3, N.4, p. 1216-1228. Manaus, 2012.

BORDALO, C. Gestão em bacia hidrográfica na Amazônia: uma reflexão das experiências de gestão em mananciais da Região Metropolitana de Belém - Pará. In: Caminhos e lugares da Amazônia: ciência, natureza e territórios. MOTA, G. [et. al.]. Caminhos e lugares da Amazônia: ciência, natureza e território. Belém: GAPTA/UFPA, 2009.

FERREIRA, D.Conflito pelo uso da água na Amazônia brasileira: Uma análise envolvendo a atividade mínerometalúrgica e as comunidades Ilha São João e Curuperé no município de Barcarena-PA. 2015. 135f. Dissertação (Mestrado em Geografia) Programa de Pós-Graduação em Geografia, Universidade Federal do Pará, Belém, 2015.

LANNA, A. Gerenciamento de Bacias Hidrográficas: aspectos conceituais e metodológicos. Brasília: IBAMA, 1995.

(Org) Técnicas quantitativas para gerenciamento de recursos hídricos. Porto Alegre: Editora da UFRGS, 1997.

LIMA, V. Conflito de uso da água no canal da Redenção: Assentamento Acauã - Aparecida-PB. 2006. 95f. Monografia de Graduação em Geografia pela Universidade Federal da Paraíba, 2006.

LIMA, R; LIMA; A. OLIVEIRA, L; TELLES, M; BARRETO, N; GUIMARÃES, P; FONTILNHAS, R. Recursos Hídricos no Estado do Pará: principais ações desenvolvidas no âmbito da gestão. In: SECTAM (Org.)

Navegando sob o céu do Pará: Hidroclimatologia e recursos hídricos do Estado do Pará. p. 59-75. Belém, 2005.

MOTA, S. Preservação e conservação de recursos hídricos. $2^{\circ}$ ed. Rio de Janeiro: ABES, 1995

RODRIGUES, J.Risco tecnológico: uma análise do Porto de Vila do Conde como área de potencial de ameaça ao vazamento de óleo para comunidades em situação de vulnerabilidade. 2008. 95f. Dissertação(Mestrado em Geografia) Programa de Pós-Graduação em Geografia, Universidade Federal do Pará, Belém, 2008.

SILVA, F. Por uma Gestão das Águas na Bacia Hidrográfica do Rio Murucupi-Barcarena-Pa.2012. 161 f. Dissertação (Mestrado em Geografia) Programa de Pós-Graduação em Geografia, Universidade Federal do Pará, Belém, 2012.

THUAL, F. Methodes de lagéopolitique. Paris: Editora Ellipses, 1996.

TORRES, A. Hidroterritórios (novos territórios da água): os instrumentos de gestão dos recursos hídricos e seus impactos nos arranjos territoriais. 2007. 121f. Dissertação (Mestrado em Geografia) - Programa de Pós-Graduação em Geografia. Universidade Federal de Pernambuco, Recife, 2007.

VIANNA, P; LIMA, V; TORRES, A. Agricultura Familiar e desertificação. In: Agricultura familiar e desertificação / Emília Moreira (Org.). João Pessoa: Editora Universitária/UFPB, 2006. 